\title{
Phenotypic Changes of Detrusor PDGFR Alpha Positive Cells in Spinal Cord Injury-Induced Detrusor Overactivity
}

Ken Lee

University of Nevada School of Medicine

\section{Sang Park}

Konkuk University School of Medicine

Pil Choi

Kangbuk Samsung Hospital, Sungkyunkwan University

\section{Seung-Bum Ryoo}

Seoul National University Hospital, Seoul National University

\section{Haeyeong Lee}

University of Nevada School of Medicine

\section{Lauren Peri}

University of Nevada School of Medicine

\section{Tong Zhou}

University of Nevada School of Medicine

\section{Robert Corrigan}

University of Nevada School of Medicine

\section{Andrew Yanez}

University of Nevada School of Medicine

\section{Suk B Moon}

Kangwon National University

\section{Brian Perrino}

University of Nevada School of Medicine

Kenton Sanders

University of Nevada School of Medicine

Sang Don Koh ( $\nabla$ skoh@medicine.nevada.edu )

University of Nevada School of Medicine

\section{Research Article}

Keywords: PDGFR, SCl, TCs, SMCs, Detrusor 
Posted Date: May 13th, 2021

DOI: https://doi.org/10.21203/rs.3.rs-505840/v1

License: (9) This work is licensed under a Creative Commons Attribution 4.0 International License. Read Full License

Version of Record: A version of this preprint was published at Scientific Reports on August 11th, 2021. See the published version at https://doi.org/10.1038/s41598-021-95781-2. 


\section{Phenotypic changes of detrusor PDGFR alpha positive cells in Spinal Cord Injury- induced Detrusor Overactivity}

Ken Lee ${ }^{1}$, Sang O Park ${ }^{2}$, Pil C Choi ${ }^{3}$, Seung-Bum Ryoo ${ }^{4}$, Haeyeong Lee ${ }^{1}$, Lauren E. Peri ${ }^{1}$, Tong Zhou ${ }^{1}$, Robert D. Corrigan ${ }^{1}$, Andrew C Yanez ${ }^{1}$, Suk B Moon ${ }^{5}$, Brian A. Perrino ${ }^{1}$, Kenton M. Sanders ${ }^{1}$, Sang Don Koh ${ }^{1 *}$

${ }^{1}$ Department of Physiology and Cell Biology, University of Nevada School of Medicine, Reno, NV 89557 USA

${ }^{2}$ Department of Emergency Medicine, Konkuk University School of Medicine, Seoul, South Korea

${ }^{3}$ Department of Emergency Medicine, Kangbuk Samsung Hospital, Sungkyunkwan University, Seoul, South Korea

${ }^{4}$ Department of Surgery, Seoul National University Hospital, Seoul National University, Seoul, South Korea

${ }^{5}$ Department of Surgery, Kangwon National University, School of Medicine, Chuncheon, South Korea

*Corresponding - Sang Don Koh, E-mail: skoh@medicine.nevada.edu,

Phone: 775-784-6908, Fax: 775-784-6903. 


\section{ABSTRACT}

Volume accommodation occurs via a novel mechanism involving interstitial cells in detrusor muscles. The interstitial cells in the bladder are PDGFRa ${ }^{+}$, and they restrain the excitability of smooth muscle at low levels and prevent the development of transient contractions (TCs). A common clinical manifestation of spinal cord injury (SCl)-induced bladder dysfunction is detrusor overactivity (DO). Although a myogenic origin of DO after $\mathrm{SCl}$ has been suggested, a mechanism for development of SCl-induced DO has not been determined. In this study we hypothesized that SCl-induced DO is related to loss of function in the regulatory mechanism provided by PDGFRa ${ }^{+}$cells. Our results showed that transcriptional expression of Pdgfra and $\mathrm{Kcnn} 3$ was decreased after SCl. Proteins encoded by these genes also decreased after $\mathrm{SCl}$, and a reduction in PDGFRa ${ }^{+}$cell density was also documented. Loss of PDGFRa ${ }^{+}$cells was due to apoptosis. TCs in ex vivo bladders during filling increased dramatically after $\mathrm{SCl}$, and this was related to the loss of regulation provided by SK channels, as we observed decreased sensitivity to apamin. These findings show that damage to the mechanism restraining muscle contraction during bladder filling that is provided by PDGFRa ${ }^{+}$cells is causative in the development of DO after SCI. 


\section{INTRODUCTION}

As the bladder fills with urine the volume increases, but during much of the filling period, intravesical pressure remains low ${ }^{1}$. This accommodation occurs even though there is a natural tendency for the detrusor smooth muscle cells (SMCs) to contract in response to stretch ${ }^{2,3}$. In fact, during bladder filling non-voiding contractions (NVCs), detected as transient increases in intraluminal pressure, occur in cystometric records from all species including human. NVCs appear to correspond to localized contractions that are also observed in ex vivo bladder preparations and have been termed as 'spontaneous phasic contractions', 'micromotions' or 'transient contractions'4-8. Transient contractions (TCs) increase as bladder filling proceeds ${ }^{4}$. Prior experiments have shown that TCs are initiated by stretch-dependent non-selective cation channels expressed by detrusor $\mathrm{SMC}^{2,3}$. Inward currents generated by these channels depolarize SMCs and activate Ltype $\mathrm{Ca}^{2+}$ channels, causing generation of $\mathrm{Ca}^{2+}$ action potentials, $\mathrm{Ca}^{2+}$ entry into SMCs and contraction. Action potentials propagate to other SMCs within the same muscle bundle, but do not spread to adjacent muscle bundles.

Several studies suggest that TCs initiate afferent nerve activity and provide a major source of the sensory information conveyed to the central nervous system during bladder filling ${ }^{9-12}$. A recent study has clearly demonstrated the link between TCs and sensory output from bladder ${ }^{4}$. Increased TCs may correspond to the sensory and mechanical behaviors associated with detrussor overactivity (DO). Normal bladders have the means to restrain development of TCs, but experiments have not been sufficiently rigorous to reveal the mechanisms responsible for restraining bladder excitability and the development of TCs during filling. 
We discovered a novel mechanism involving interstitial cells in detrusor muscles. Interstitial cells of the bladder were previously identified as c-Kit ${ }^{+}$cells and thought to provide excitatory input to the detrusor ${ }^{13,14}$, but more recent immunohistochemical evaluation showed few $\mathrm{c}^{-K i t^{+}}$cells, other than mast cells, in the bladder of several species $^{15}$. In fact, the interstitial cells in the bladder are PDGFRa ${ }^{+}$, and they provide inhibitory regulation of detrusor muscles ${ }^{16-20}$. Inhibitory regulation is enhanced by purines and by stretch, making it an ideal mechanism for regulating detrusor excitability and restraining TCs during bladder filling. Rigorous confirmation of the hypothesis that inhibitory regulation during bladder filling is provided by PDGFR $\alpha^{+}$cells would be to demonstrate that pathological conditions in which DO develops are associated with loss or remodeling of PDGFRa ${ }^{+}$cells. Therefore, we evaluated the status of PDGFRa ${ }^{+}$cells in spinal cord injury (SCI) animal models that are known to develop DO.

Clinical manifestations of SCl-induced bladder dysfunction involve a combination of storage and voiding problems. A myogenic origin of $\mathrm{DO}$ after $\mathrm{SCl}$ has also been suggested due to abnormal muscle reactivity ("the myogenic hypothesis") ${ }^{21}$ without studying precise mechanisms for DO after SCl. Since obtaining human whole bladder due to $\mathrm{SCl}$ is extremely difficult, we investigated the mechanisms of DO in the acute phase of SCl using murine model. 


\section{RESULTS}

1. Changes in transcriptional expression of SCl-induced detrusor muscles

We harvested detrusor muscles from control (sham) mice and 1, 2, 3, 7, 14 and 30 days after SCl. Pdgfra and Kcnn3 expression were decreased in detrusor muscles $24 \mathrm{hr}$ after SCl. Reduced Pdgfra and Kcnn3 expression persisted for at least 1 month after SCl $\left(n=4\right.$, Fig. 1A \& B). Pdgfra and Kcnn3 expression also decreased in sorted PDGFR $\alpha^{+}$ cells 7days after $\mathrm{SCl}$, as compared with sorted PDGFR $\alpha^{+}$cells from sham mice ( $\mathrm{n}=4$, Fig. 1C). We also isolated and sorted SMCs from smMHC/eGFP mice. Expression of Myh11 (SM myosin heavy chain), Kcnma1 (BK $\left.\alpha_{\text {slo }}\right)$ and Cacna1C (Cav1.2) were unchanged in SMCs after SCI (n=4, Fig. 1D).

\section{Changes in protein expression in SCl-induced detrusor muscles}

Three approaches were used to characterize changes in protein expression. Firstly, immunohistochemistry was used to examine the expression and distribution of PDGFRa and SK3 immunoreacitvity in SCI. PDFGR $\alpha$ and SK3-like immunoreactivity decreased in detrusor muscles after $\mathrm{SCl}$ in a time dependent manner (Fig. 2). We also used PDFGRa/eGFP mice to examine the density of green nuclei in control and SCl. The density of eGFP were decreased in $\mathrm{SCl}$ (3 day and 7day) compared to control. Since SCI can show bladder distension, we normalized the eGFP expression by calculated the surface area (e.g. $63 \mathrm{~mm}^{2}$ in control vs $111 \mathrm{~mm}^{2}$ in $\mathrm{SCl}, \mathrm{n}=3$, respectively). PDGFRa ${ }^{+}$ cells also decreased to 53\% (3 day) and 35\% (7 day) after SCI in PDGFRa/eGFP mice, (Fig. 3A-C). We confirmed these findings by Western analysis and verified reduction in PDGFRa protein in detrusor muscles of $\mathrm{SCl}$ mice $(n=4$, Fig. 3D \& E). These findings were 
consistent with the transcriptional changes observed after SCl (see Fig. 1), and suggest overall reduction in PDGFRa ${ }^{+}$cells and reduced expression of SK3 that would negatively impact the regulation of excitability provided by PDGFRa ${ }^{+}$cells in the bladder.

\section{Apoptosis of PDGFR $\alpha^{+}$cells in SCI}

We examined changes in the expression of apoptosis pathways to better understand the fate of PDGFRa ${ }^{+}$cells after SCI. RNA-seq of whole muscle samples showed geneset scores computed for the apoptosis-related KEGG and GOBP terms, respectively, using the FAIME algorithm ${ }^{22}$. The apoptosis-related geneset score was significantly increased (t-test: $P<0.05$ ) in detrusor muscles after SCl (Fig. 4A). Apoptosis-related genes, including Apaf1, Capns1, and Casp3, were significantly upregulated (FC>1.5 and FDR $<0.05$ ) in detrusor muscles 3 days after SCl (Fig. 4B). Time dependent increases in expression of Apaf1 (Fig. 4C) and Caspase3 (Fig, 4D) in detrusor muscles after SCl (as compared to sham; $\mathrm{n}=4$ for each period) were confirmed by qPCR.

\section{Ex vivo preparation to confirm the role of PDGFR $\alpha^{+}$cells in SCI}

Ex vivo bladder preparations were used to characterize the relationship between intravesical volumes and pressures in bladders after SCl. Pressure-volume studies done ex vivo exclude extrinsic neural reflexes during filling. SK channels are highly expressed in detrusor PDGFRa ${ }^{+}$cells, and antagonists of these channels increase TCs during filling ${ }^{17}$. We examined the effects of the SK channel antagonist, Apamin (300nM) on bladders from control and $\mathrm{SCl}$ (up to 1 month).

In sham preparations, infusion of Krebs-Ringer bicarbonate $(20 \mu \mathrm{l} / \mathrm{min})$ generated repeatable responses consisting of small amplitude, low frequency of TCs (Fig. 5A). 
Apamin (300 $\mathrm{nM}$ added to the bathing solution) increased the amplitude $(6.9 \pm 1.2 \mathrm{cmH} 2 \mathrm{O}$, $\mathrm{P}<0.01)$ and frequency $(65 \pm 12$ events, $\mathrm{P}<0.01, \mathrm{n}=11)$ of TCs during bladder filling, as compared to control $\left(2.1 \pm 0.5 \mathrm{cmH}_{2} \mathrm{O}\right.$ in amplitude and $22 \pm 9.1$ events in frequency; Fig. 5A, Table 1). At 1, 3, 7, 14 and 30 days after $\mathrm{SCl}$, the amplitude and frequency of TCs during filling were increased (Fig. 5B-F, Table 1). Enhanced TCs during filling persisted for at least 30 days after $\mathrm{SCl}$, and apamin failed to induce significant changes of amplitude (from 7 days) and frequency (from 1 day) of TCs after SCl (Fig. 5B-F, Table 1) indicating that development of DO after $\mathrm{SCl}$ progressed for up to 1 month after $\mathrm{SCl}$. Bladder capacity and filling time to reach $30 \mathrm{cmH}_{2} \mathrm{O}$ were also increased in all of $\mathrm{SCl}$ groups compared to sham (Table 2). The enlarged bladder capacity due to lack of voluntary voiding and prolonged infusion time was prominent in 30 days. 


\section{DISCUSSION}

In this study we investigated responses of the murine bladder and the status of PDGFRa ${ }^{+}$cells after SCl. PDGFRa ${ }^{+}$cells and the functions provided by these cells in regulating bladder contractions during filling were greatly decreased after $\mathrm{SCl}$. TCs increased dramatically during bladder filling, and accompanying this change in function, Pdgfra and Kcnn3 expression decreased. Expression of PDGFRa and SK3 protein also decreased. Detrusor muscles displayed apoptotic loss of PDGFRa ${ }^{+}$cells. The increase in TCs was due to decreased sensitivity to apamin during bladder filling, which is consistent with the reduction in expression of SK3 and loss of PDGFRa ${ }^{+}$cells that express SK3 channels. These findings demonstrate a novel mechanism for development of DO after $\mathrm{SCl}$ that is linked to loss of the inhibitory regulation provided by PDGFRa ${ }^{+}$cells during bladder filling.

$\mathrm{PDGFRa}^{+}$cells regulate detrusor excitability during bladder filling ${ }^{23}$. SK channel antagonists potentiate the amplitude of spontaneous contractions in murine ${ }^{24}$, guinea $\mathrm{pig}^{25}$ and human ${ }^{26}$ detrusor muscles. The effects of apamin are likely due to blocking SK channels in PDGFRa ${ }^{+}$cells which have a high expression of SK3 channels, because the current density from SK channels is minimal in SMCs and not even resolvable in murine SMCs at physiological potentials ${ }^{27}$. Thus, PDGFRa ${ }^{+}$cells express a powerful mechanism to suppress excitability and allow the bladder to fill with minimal activation of TCs and sensory discharge ${ }^{23}$. Downregulation of Pdgfra and Kcnn3 genes can lead to the development of DO after $\mathrm{SCl}$. Indeed, transcriptional analysis revealed downregulation of Pdgfra and Kcnn3 in early stage of SCl bladder. 
IHC showed that the distribution of PDGFRa ${ }^{+}$cells decreases in detrusor muscles after SCl. The immunohistochemistry findings were confirmed using a reporter strain of mice with expression of eGFP in nuclei of PDGFRa ${ }^{+}$cells, as a relatively low density of $\mathrm{eGFP}^{+}$cells was found in bladders of PDGFRa/eGFP mice after SCl. However, IHC is not reliable method to quantify loss of protein, so protein expression in extracts of detrusor muscles was measured by Western analyses. Western blots showed the downregulation of PDGFRa expression and SK3 expression which was mirrored by transcriptional expression.

Loss of PDGFRa ${ }^{+}$cells caused by SCl were due to apoptotic changes in detrusor PDGFRa ${ }^{+}$cells although the mechanism inducing apoptosis in detrusor PDGFRa ${ }^{+}$cells by $\mathrm{SCl}$ has not been elucidated. Apaf1 as well as caspase 3 had a trend to be increased after $\mathrm{SCl}$ compare to sham indicating that cell death occurred as a result of $\mathrm{SCl}$. We speculate that apoptosis of PDGFRa $\alpha^{+}$cells may be caused by the reduced expression and function of neurotropins ${ }^{28,29}$. The mechanism causing damage to the regulatory function provided by PDGFRa ${ }^{+}$cells after $\mathrm{SCl}$ is an important topic for future research.

Ex vivo preparations were used in the present study to isolate bladders and exclude connections from central and spinal reflexes. Release of mediators from the urothelium may also influence detrusor excitability, but substances and receptors involved in such a mechanism have not been identified. Ex vivo bladder developed increased TCs after $\mathrm{SCl}$ as compared to sham bladders (see Table 1), and enhanced TCs persisted for at least 30 days after $\mathrm{SCl}$. Effects of apamin on responses to bladder filling remained for up to $72 \mathrm{hr}$ after $\mathrm{SCl}$, but the sensitivity to apamin decreased after $\mathrm{SCl}$ due to partial loss 
of PDGFRa ${ }^{+}$cells and downregulation of SK3 channels. These findings present in ex vivo bladders suggest that myogenic mechanisms are sufficient to generate DO.

$\mathrm{SCl}$ patients have less opportunity to see a urologist due to other complications that often need to be treated ahead of bladder dysfunction. This prevents patients from early and appropriate examination and treatment of lower urinary tract dysfunction in the early phase of $\mathrm{SCl}$. Although there are many reports of DO after recovery from spinal shock $^{30-35}$, only a few reports confirm development of $\mathrm{DO}$ in the acute phase of $\mathrm{SCl}$ (i.e. $3-40$ days after SCI $)^{36,37}$. Early treatment to avoid higher intravesical pressure with lower bladder compliance followed by vesicoureteral reflux associated with DO has been suggested to keep patients' renal and bladder function serving as a 'low pressure tank' without waiting for the irreversible complications of $\mathrm{SCl} 36,37$. Given the importance of an early intervention for a treatment especially focusing on a myogenic aspect, preventing the phenotypic change of PDGFRa ${ }^{+}$cells and rescuing the function of SK channels in bladder PDGFRa ${ }^{+}$cells might be a promising target to avoid development of DO after $\mathrm{SCl}$. 


\section{METHODS}

Spinal cord injury (SCI) animal model

All experimental procedures were conducted in accordance with the National Institutes of Health Guide for the Care and Use of Laboratory Animals and the animal use protocol, reviewed and approved by the Institutional Animal Use and Care Committee at the University of Nevada. C57BL/6 (male mice, 8-12 wks old), Pdgfratm11(EGFP)Sor/J (PDGFRa/eGFP, Jackson lab) and smMHC/Cre/eGFP (SMC/eGFP) from Jackson Lab used for SCl operations and age-matched control. Laminectomies were performed under isoflurane anesthesia ( $3-4 \%$ with a balance of oxygen for induction followed by $2 \%$ for maintenance), and the spinal cord (T11-T13) were exposed without any damage or compression to the surrounding dura. Dumont \#5 forceps were positioned in the middle of the exposed spinal cord segment to perform complete spinal cord transection. Complete spinal cord transection was done at T12 confirmed by retraction of rostal and caudal cut ends of spinal cord under surgical microscope, which had a space approximately at $2 \mathrm{~mm}$. Control animals received sham operations with exposing the vertebrae at same level as $\mathrm{SCl}$ without damaging any spinal cord and dura. Enrofloxacin ( $5 \mathrm{mg} / \mathrm{kg}$ ) was applied subcutaneously for three days after $\mathrm{SCl}$ followed by twice a week after $\mathrm{SCl}$ surgery until ex vivo or molecular evaluation was done. The bladder was manually squeezed to eliminate the residual urine of bladder once daily. Bladders were collected for experiments at $1,3,7,14$ and 30 days after $\mathrm{SCl}$ surgery and in sham control.

Ex vivo preparation

Bladders were removed. A PE50 catheter (Intramedic, Fisher Scientific, Santa Clara, CA) 
with a cuff was placed in the urethral opening and ligated tightly with silk thread just above the ureterovesical junction and constant monitoring of pressure. Intravesical pressure were recorded with reference to atmospheric pressure $(p=0)$ at the level of the bladder connected to a quad-bridge amplifier (AD Instruments) interfaced to a computer. KrebsRinger bicarbonate solution $\left(37^{\circ} \mathrm{C}\right)$ was infused $(25 \mu \mathrm{l} / \mathrm{min})$ and stopped when bladder pressures reach $30-40 \mathrm{~cm} / \mathrm{H}_{2} \mathrm{O}$ to avoid a permanent damage ${ }^{4}$. At least 3 fills will be performed under each experimental condition to ensure reproducibility. The effect of apamin was tested on sham and spinal cord injured bladder. Ex vivo data were captured using the threshold search by Clampfit 10 (Molecular Device) with baseline adjustment to examine the frequency and amplitude of transient contractions occurring during the filling phase.

\section{Molecular preparation}

Dissection of detrusor smooth muscles and RNA isolation in sham and $\mathrm{SCl}$ were identical as previously described ${ }^{18}$. For quantitative analysis of transcripts, PDGFRa ${ }^{+}$cells and SMC/eGFP were purified by fluorescence-activated cell sorting and detrusor muscles for molecular tests. Total RNA was isolated from detrusor muscles, PDGFRa ${ }^{+}$cells and SMC/eGFP using illustra RNAspin Mini RNA Isolation kit (GE Healthcare, Little Chalfont, UK), and first-strand cDNA was synthesized using SuperScript III (Invitrogen, Carlsbad, CA, USA), according to the manufacturer's instructions. PCR was performed with specific primers using Go-Taq Green Master Mix (Promega Corp., Madison, WI, USA). The following PCR primers designed against murine sequences were used (GenBank accession number is given in parentheses for the reference nucleotide 
sequence used): Pdgfra (NM_011058) and Kcnn3 (NM_080466). Quantitative PCR (qPCR) was performed with the same primers as PCR using Fast SYBR Green chemistry (Applied Biosystems, Foster City, CA, USA) on the 7900HT Real Time PCR System (Applied Biosystems). Regression analysis of the mean values of three multiplex qPCRs for the $\log _{10}$-diluted cDNA was used to generate standard curves. Unknown amounts of messenger RNA (mRNA) were plotted relative to the standard curve for each set of primers and graphically plotted using Microsoft Excel. This gave transcriptional quantification of each gene relative to the endogenous glyceraldehyde 3-phosphate dehydrogenase (Gapdh) standard after log transformation of the corresponding raw data.

Transcriptomes profiled by mRNA-seq (Novogene Co Ltd) were investigated to identify the genes and pathways potentially involved in the regulation of excitability in PDGFRa ${ }^{+}$cells upon $\mathrm{SCl}$ treatment. Total RNA was obtained from detrusor muscles in sham and $\mathrm{SCl}$. Using the SAM tool ${ }^{38}$, the genes with false discovery rate (FDR) $<5 \%$ and fold change $(\mathrm{FC})>1.5 \%$ were deemed to be differentially expressed. The FAIME algorithm ${ }^{22}$ was applied to assign gene expression-based geneset scores for the "apoptosis" related genes defined by both the Kyoto Encyclopedia of Genes and Genomes (KEGG) $)^{39}$ and Gene Ontology $(\mathrm{GO})^{40}$ databases. The FAIME method generates geneset scores using the rank-weighted gene expression of individual samples, which determines whether an a priori defined set of genes shows statistically significant, concordant expression differences between two biological states (e.g. sham vs. SCl), and provides a mechanistic interpretation of the deregulated genes. 
Whole mount immunohistochemistry

C57BL/6 and Pdgfratm11(EGFP)Sor/J bladders were cut open from the neck up to the dome. Tissues were dissected in Krebs ringer solution containing $118.5 \mathrm{mM} \mathrm{NaCl}$, $4.7 \mathrm{mM} \mathrm{KCl}, 2.5 \mathrm{mM} \mathrm{CaCl}_{2}, 1.2 \mathrm{mM} \mathrm{MgCl}_{2}, 23.8 \mathrm{mM} \mathrm{NaHCO}_{3}, 1.2 \mathrm{mM} \mathrm{KH}_{2} \mathrm{PO} 4$ and $11 \mathrm{mM}$ dextrose, then pinned down on Sylgard dish and stretched $150 \%$ from the resting state. For urothelial denudation, urothelium was removed and surface of the muscle was scraped to remove any residual sub-urothelial cells. Fixation and incubation of tissues were identical as previously described ${ }^{16}$. For double labelling studies, tissues were reblocked for $1 \mathrm{hr}$ in 10\% normal donkey serum (Sigma-Aldrich) and incubated overnight in antibody of choice, diluted in $0.5 \%$ Triton-X (Sigma-Aldrich) and incubated in the appropriate Alexa Fluor (Invitrogen) antibody diluted 1:1000 in PBS for $1 \mathrm{hr}$. Processed tissues were mounted with Aqua mount mounting media (Lerner Laboratories, Pittsburgh, PA, USA) on glass slides and cover slipped and imaged. The primary antibodies of PDGFRa (R\&D Systems, Inc.) and SK3 (Alamone Labs) were used and primary antibodies were omitted in the procedure for negative controls.

\section{Automated Capillary Electrophoresis and Chemiluminescent Western Blotting}

Muscles were snap-frozen in liquid $\mathrm{N}_{2}$, and stored at $-80^{\circ} \mathrm{C}$. For analysis, the methods for homogenization, centrifugation and collection of the supernatants were identical as previously reported ${ }^{41,42}$. Protein concentrations were determined by Bradford assay $^{42}$. Analysis of protein expression was performed according to the User Guide using a ProteinSimple Wes instrument (CA, USA). Each sample was mixed with fluorescent $5 x$ Master Mix, incubated at $95^{\circ} \mathrm{C}$ for $5 \mathrm{~min}$ and then loaded into a Wes $12-230 \mathrm{kDa}$ prefilled 
plate, along with a biotinylated protein ladder, blocking buffer, primary antibodies, ProteinSimple HRP-conjugated anti-rabbit secondary antibody, luminol peroxide, and washing buffer. The plates and capillary cartridges were placed into the Wes for electrophoresis and chemiluminescence immunodetection by a CCD camera using default settings. Compass software was used to acquire and analyze the data and generate gel images and chemiluminescence intensities. Protein expression levels are expressed as the chemiluminescence intensity area under the primary antibody peak per $\mu g$ protein.

Drugs

All reagents were purchased from Sigma-Aldrich (St Louis, MO, USA) and apamin (Tocris, UK) solubilized in the bath solution for ex vivo recordings.

Statistical analyses

All data are expressed as means \pm SEM. " $n$ " represents the number of experiments. All statistical analyses were performed using GraphPad Prism. A paired and unpaired Student's $t$ test was used to compare groups of data and differences were considered to be significant at $P<0.05$. This study was carried out in compliance with the ARRIVE guidelines. 
Funding: This research was supported by the NIH/NIDDK R01 DK098388 for SDK.

Author Information:

Affiliations

Department of Physiology and Cell Biology, University of Nevada School of Medicine, Reno, NV 89557 USA

Ken Lee, Haeyeong Lee, Lauren E. Peri, Tong Zhou, Robert D. Corrigan, Andrew C Yanez, Brian A. Perrino, Kenton M. Sanders \& Sang Don Koh

Department of Emergency Medicine, Konkuk University School of Medicine, Seoul, South Korea

Sang O Park

Department of Emergency Medicine, Kangbuk Samsung Hospital, Sungkyunkwan University, Seoul, South Korea

Pil C Choi

Department of Surgery, Seoul National University Hospital, Seoul National University, Seoul, South Korea

Seung-Bum Ryoo

Department of Surgery, Kangwon National University, School of Medicine, Chuncheon, South Korea

Suk B Moon

Authors' contributions: SOP, PCC, S-BR, SBM and HL performed spinal cord surgery. Ex vivo data were collected and analyzed by SOP, PCC, S-BR, RDC, ACY, SBM and HL. $\mathrm{HL}$ and LEP performed cell sorting and molecular study. TZ analyzed RNA-seq data. Immunohistochemistry were performed by ACY and SBM and WES were performed by BAP. KMS and SDK shared in the design of experiments, interpretation of the data and the writing of the manuscript. All authors approved the final version of the manuscript.

Competing interests: No conflict of interest 


\section{References}

1 Wein, A. J. Normal and abnormal function: An overview, Bladder Dysfunction in the Adult: The basis for Clinical Management, Current Clinical Urology. Springer Science+Business Media New Yoork. p. 19-22. (2014)

2 Wellner, M. C. \& Isenberg, G. Properties of stretch-activated channels in myocytes from the guinea-pig urinary bladder. J Physiol 466, 213-227 (1993).

3 Wellner, M. C. \& Isenberg, G. Stretch effects on whole-cell currents of guinea-pig urinary bladder myocytes. J Physiol 480 ( Pt 3), 439-448 (1994).

4 Heppner, T. J., Tykocki, N. R., Hill-Eubanks, D. \& Nelson, M. T. Transient contractions of urinary bladder smooth muscle are drivers of afferent nerve activity during filling. J Gen Physiol 147, 323-335, doi:10.1085/jgp.201511550 (2016).

5 Drake, M. J. et al. Partial outlet obstruction enhances modular autonomous activity in the isolated rat bladder. $J$ Urol 170, 276-279, doi:10.1097/01.ju.0000069722.35137.e0 (2003).

6 Gillespie, J. I. Phosphodiesterase-linked inhibition of nonmicturition activity in the isolated bladder. BJU Int 93, 1325-1332, doi:10.1111/j.1464-410X.2004.04840.x (2004).

7 Parsons, B. A., Drake, M. J., Gammie, A., Fry, C. H. \& Vahabi, B. The validation of a functional, isolated pig bladder model for physiological experimentation. Front Pharmacol 3, 52, doi:10.3389/fphar.2012.00052 (2012).

8 Vahabi, B. \& Drake, M. J. Physiological and pathophysiological implications of micromotion activity in urinary bladder function. Acta Physiol (Oxf) 213, 360-370, doi:10.1111/apha.12373 (2015).

9 lijima, K., Igawa, Y., Wyndaele, J. J. \& De Wachter, S. Mechanosensitive primary bladder afferent activity in rats with and without spinal cord transection. $J$ Urol 182, 2504-2510, doi:10.1016/j.juro.2009.07.012 (2009).

10 Kanai, A. \& Andersson, K. E. Bladder afferent signaling: recent findings. J Urol 183, 1288-1295, doi:10.1016/j.juro.2009.12.060 (2010).

11 Satchell, P. \& Vaughan, C. Efferent pelvic nerve activity, ganglionic filtering, and the feline bladder. Am J Physiol 256, R1269-1273 (1989).

$12 \mathrm{Yu}, \mathrm{Y}$. \& de Groat, W. C. Sensitization of pelvic afferent nerves in the in vitro rat urinary bladder-pelvic nerve preparation by purinergic agonists and cyclophosphamide pretreatment. Am J Physiol Renal Physiol 294, F1146-1156, doi:10.1152/ajprenal.00592.2007 (2008).

13 McCloskey, K. D. et al. Comparison of mechanical and electrical activity and interstitial cells of Cajal in urinary bladders from wild-type and W/Wv mice. Br J Pharmacol 156, 273-283, doi:10.1111/j.1476-5381.2008.00006.x (2009).

14 McCloskey, K. D. \& Gurney, A. M. Kit positive cells in the guinea pig bladder. $J$ Urol 168, 832-836 (2002).

15 Gevaert, T. et al. The stem cell growth factor receptor KIT is not expressed on interstitial cells in bladder. $J$ Cell Mol Med 21, 1206-1216, doi:10.1111/jcmm.13054 (2017). 
16 Koh, B. H. et al. Platelet-derived growth factor receptor-alpha cells in mouse urinary bladder: a new class of interstitial cells. J Cell Mol Med 16, 691-700, doi:10.1111/j.1582-4934.2011.01506.x (2012).

17 Lee, H. et al. Premature contractions of the bladder are suppressed by interactions between TRPV4 and SK3 channels in murine detrusor PDGFRalpha+ cells. Sci Rep 7, 12245, doi:10.1038/s41598-017-12561-7 (2017).

18 Lee, H., Koh, B. H., Peri, L. E., Sanders, K. M. \& Koh, S. D. Functional expression of SK channels in murine detrusor PDGFR+ cells. J Physiol 591, 503513, doi:10.1113/jphysiol.2012.241505 (2013).

19 Lee, H., Koh, B. H., Peri, L. E., Sanders, K. M. \& Koh, S. D. Purinergic inhibitory regulation of murine detrusor muscles mediated by PDGFRalpha+ interstitial cells. J Physiol 592, 1283-1293, doi:10.1113/jphysiol.2013.267989 (2014).

20 Lee, $\mathrm{H}$. et al. UTP activates small-conductance Ca2+-activated $\mathrm{K}+$ channels in murine detrusor PDGFRalpha+ cells. Am J Physiol Renal Physiol 309, F569-574, doi:10.1152/ajprenal.00156.2015 (2015).

21 Brading, A. F. \& Turner, W. H. The unstable bladder: towards a common mechanism. Br J Urol 73, 3-8 (1994).

22 Yang, X. et al. Single sample expression-anchored mechanisms predict survival in head and neck cancer. PLoS Comput Biol 8, e1002350, doi:10.1371/journal.pcbi.1002350 (2012).

23 Koh, S. D., Lee, H., Ward, S. M. \& Sanders, K. M. The Mystery of the Interstitial Cells in the Urinary Bladder. Annu Rev Pharmacol Toxicol, doi:10.1146/annurevpharmtox-010617-052615 (2017).

24 Thorneloe, K. S. et al. Small-conductance, $\mathrm{Ca}(2+)$-activated $\mathrm{K}+$ channel 2 is the key functional component of SK channels in mouse urinary bladder. Am J Physiol Regul Integr Comp Physiol 294, R1737-1743, doi:10.1152/ajpregu.00840.2006 (2008).

25 Parajuli, S. P., Soder, R. P., Hristov, K. L. \& Petkov, G. V. Pharmacological activation of small conductance calcium-activated potassium channels with naphtho[1,2-d]thiazol-2-ylamine decreases guinea pig detrusor smooth muscle excitability and contractility. J Pharmacol Exp Ther 340, 114-123, doi:10.1124/jpet.111.186213 (2012).

26 Afeli, S. A., Rovner, E. S. \& Petkov, G. V. SK but not IK channels regulate human detrusor smooth muscle spontaneous and nerve-evoked contractions. Am J Physiol Renal Physiol 303, F559-568, doi:10.1152/ajprenal.00615.2011 (2012).

27 Herrera, G. M. et al. Urinary bladder instability induced by selective suppression of the murine small conductance calcium-activated potassium (SK3) channel. $J$ Physiol 551, 893-903, doi:10.1113/jphysiol.2003.045914 (2003).

28 McEvilly, R. J. et al. Requirement for Brn-3.0 in differentiation and survival of sensory and motor neurons. Nature 384, 574-577, doi:10.1038/384574a0 (1996).

29 Yoon, S. O., Casaccia-Bonnefil, P., Carter, B. \& Chao, M. V. Competitive signaling between TrkA and p75 nerve growth factor receptors determines cell survival. J Neurosci 18, 3273-3281 (1998).

30 de Groat, W. C. A neurologic basis for the overactive bladder. Urology 50, 36-52; discussion 53-36 (1997). 
31 Choudhary, M., van Asselt, E., van Mastrigt, R. \& Clavica, F. Neurophysiological modeling of bladder afferent activity in the rat overactive bladder model. $J$ Physiol Sci 65, 329-338, doi:10.1007/s12576-015-0370-y (2015).

32 Coelho, A., Oliveira, R., Cruz, F. \& Cruz, C. D. Impairment of sensory afferents by intrathecal administration of botulinum toxin $A$ improves neurogenic detrusor overactivity in chronic spinal cord injured rats. Exp Neurol 285, 159-166, doi:10.1016/j.expneurol.2016.05.029 (2016).

33 Dorsher, P. T. \& McIntosh, P. M. Neurogenic bladder. Adv Urol 2012, 816274, doi:10.1155/2012/816274 (2012).

34 Miyazato, M., Yoshimura, N. \& Chancellor, M. B. The other bladder syndrome: underactive bladder. Rev Urol 15, 11-22 (2013).

35 Taweel, W. A. \& Seyam, R. Neurogenic bladder in spinal cord injury patients. Res Rep Urol 7, 85-99, doi:10.2147/RRU.S29644 (2015).

36 Bywater, M., Tornic, J., Mehnert, U. \& Kessler, T. M. Detrusor Acontractility after Acute Spinal Cord Injury-Myth or Reality? J Urol 199, 1565-1570, doi:10.1016/j.juro.2018.01.046 (2018).

37 Watanabe, T. et al. High incidence of occult neurogenic bladder dysfunction in neurologically intact patients with thoracolumbar spinal injuries. $J$ Urol 159, 965968 (1998).

38 Tusher, V. G., Tibshirani, R. \& Chu, G. Significance analysis of microarrays applied to the ionizing radiation response. Proc Natl Acad Sci U S A 98, 51165121, doi:10.1073/pnas.091062498 (2001).

39 Kanehisa, M. \& Goto, S. KEGG: kyoto encyclopedia of genes and genomes. Nucleic Acids Res 28, 27-30, doi:10.1093/nar/28.1.27 (2000).

40 Ashburner, M. et al. Gene ontology: tool for the unification of biology. The Gene Ontology Consortium. Nat Genet 25, 25-29, doi:10.1038/75556 (2000).

41 Dudem, S. et al. LINGO1 is a regulatory subunit of large conductance, $\mathrm{Ca}(2+)-$ activated potassium channels. Proc Natl Acad Sci U S A 117, 2194-2200, doi:10.1073/pnas.1916715117 (2020).

42 Li, W., Sasse, K. C., Bayguinov, Y., Ward, S. M. \& Perrino, B. A. Contractile Protein Expression and Phosphorylation and Contractility of Gastric Smooth Muscles from Obese Patients and Patients with Obesity and Diabetes. $J$ Diabetes Res 2018, 8743874, doi:10.1155/2018/8743874 (2018). 




B. Konn3
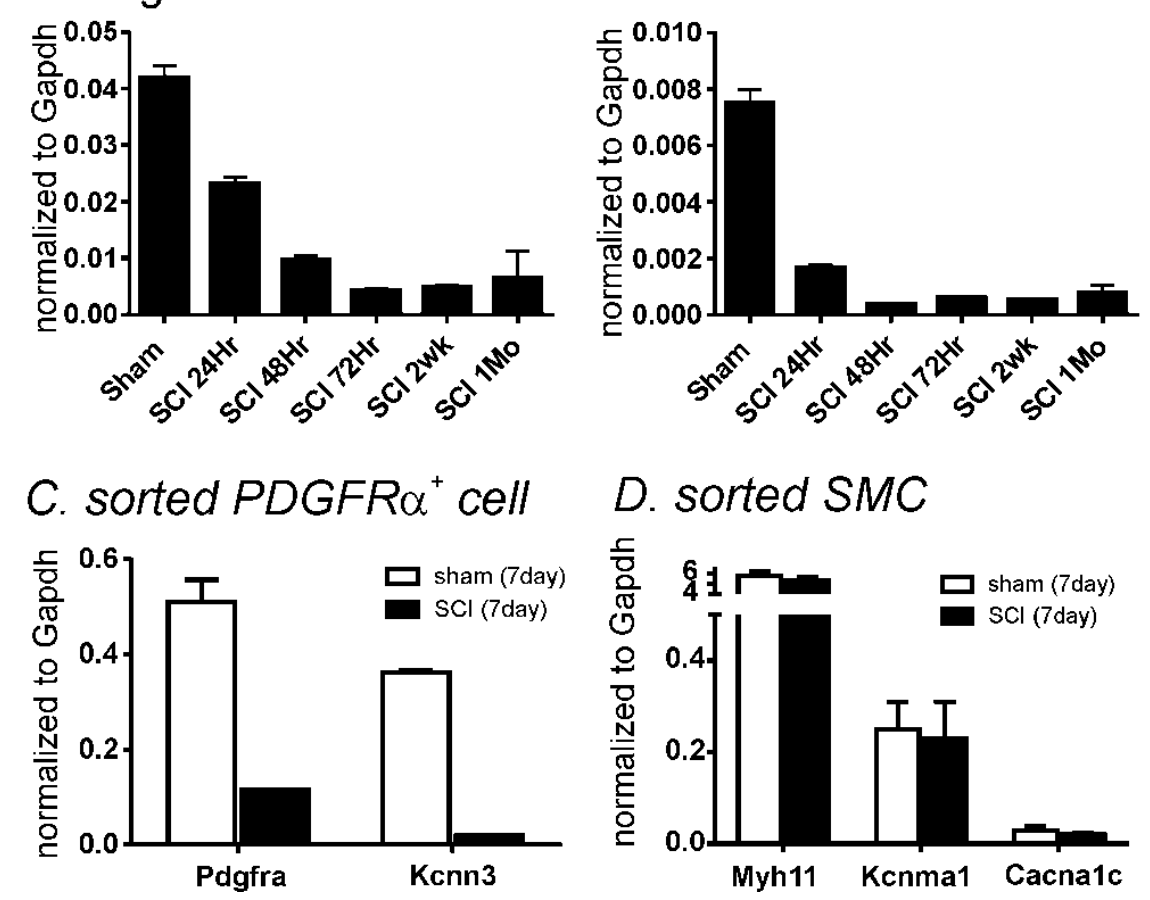

Figure 1. Quantitative analysis of transcripts in Sham and after SCI. A\&B. Pdgfra and $K c n n 3$ transcripts are decreased up to 1 month after $\mathrm{SCl}$ in detrusor muscles. $\boldsymbol{C}$. Transcripts of Pdgfra and Kcnn3 from sorted PDGFRa ${ }^{+}$cells in SCl (7day) decreased compared to sham (7day). D. Transcripts including Myh11, Kcnma1 and Cacna1C from sorted SMCs showed no significant change in SCl (7day). Error bars denote standard deviation from $n=4$. 


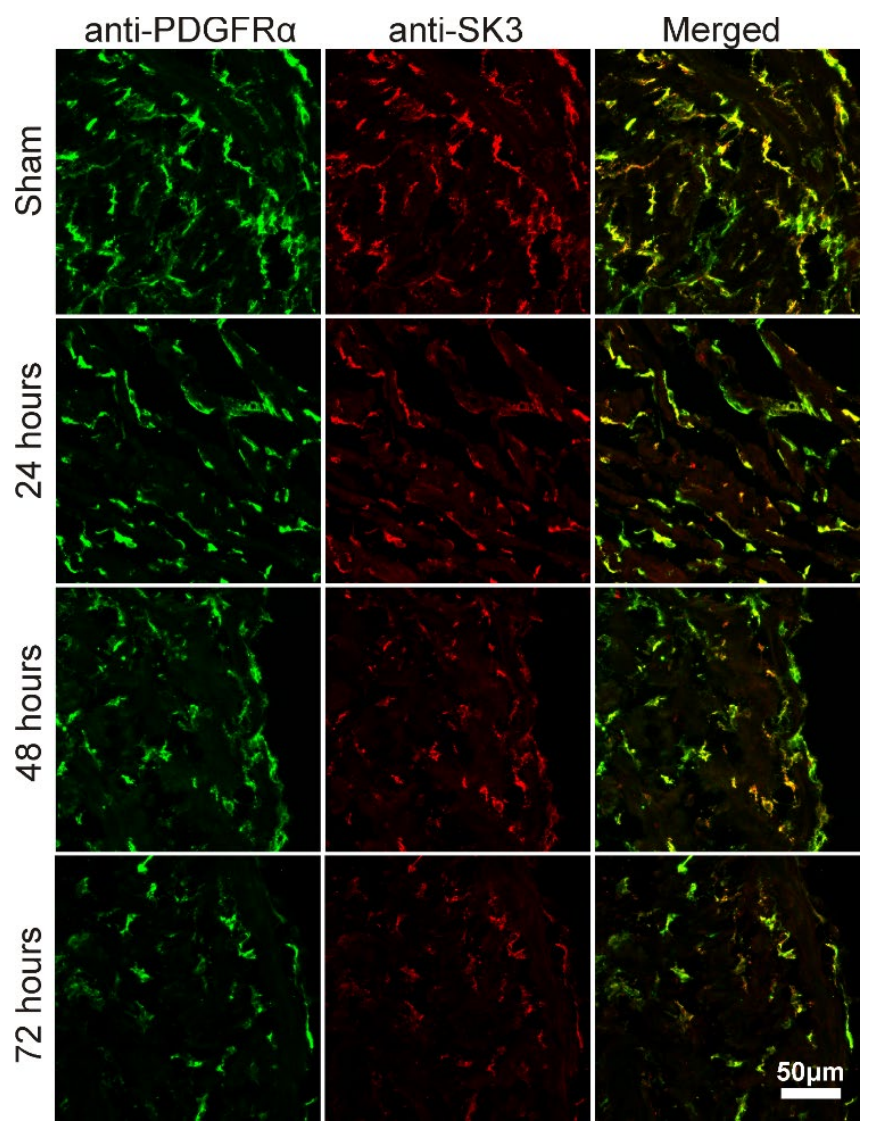

Figure 2. PDGFRa immunoreactivity of detrusor muscle layer in control and SCl. Immunoreactivity of PDGFRa (green) and SK3 (red) in control (sham). SCl (24hr, 48hr and $72 \mathrm{hr}$ ). 



Fig. 3. Density of PDFGRa/eGFP cells and Microcapillary electrophoresis and immunodetection of PDGFRa by WES in control and SCl detrusor muscles. A-C. Far fewer eGFP ${ }^{+}$nuclei (reporter for PDGFRa ${ }^{+}$cells) were found in detrusor muscles after $\mathrm{SCl}$. D. Representative Wes full length gel image of PDGFRa expression in murine detrusor muscles following SCl. $100,000 \times$ g pellet, $1 \mu \mathrm{g} /$ lane, $\gamma$-action was used for normalization. $\boldsymbol{E}$. Normalized signal intensities of PDGFRa by g-actin following $\mathrm{SCl}$ periods. 



C. Apaf1 (qPCR)

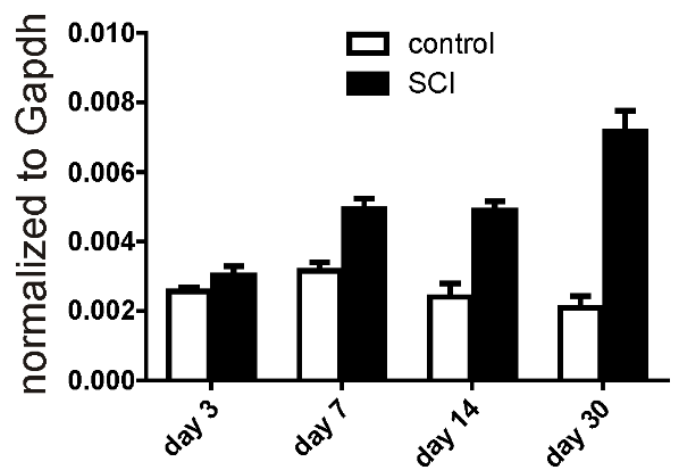

\section{Caspase $3(q P C R)$}

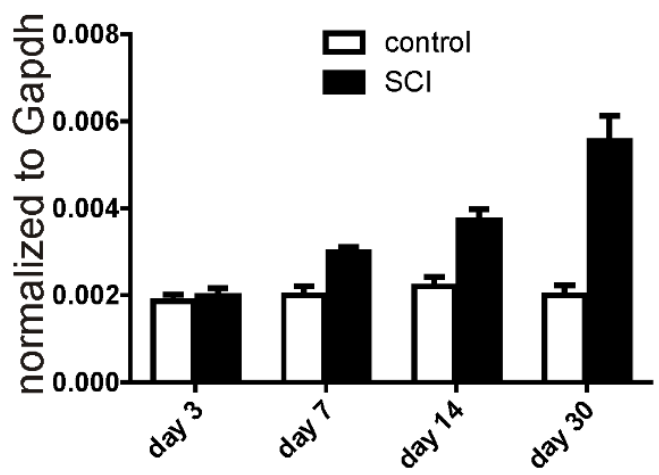

Fig. 4. SCl -induced alteration in apoptosis-related genes by RNA-seq (A \&B) and $\mathrm{qPCR}$ (C \& D). A. Apoptosis geneset scores upregulated in SCl for both the KEGG and GOBP definitions. B. Expression of three apoptosis-related genes were upregulated in SCl. C \& $D$. qPCR from sorted PDGFRa ${ }^{+}$cells in SCl up to 30days showed an increase in apoptosis-related transcripts (Apaf1 in C and Caspase 3 in D). 
A. Sham

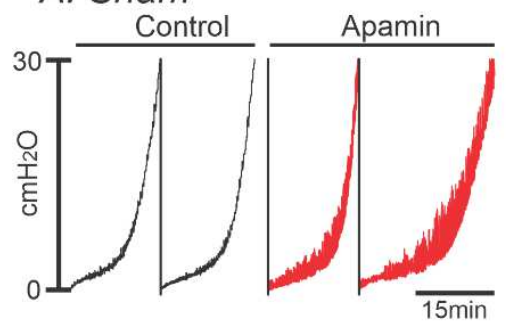

Aa. control

Ab. apamin

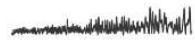

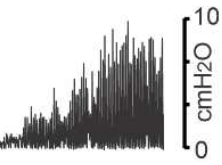

D. $7 d$ after SCl

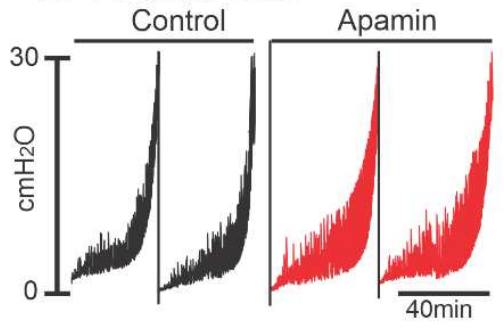

Da. control

Db. apamin

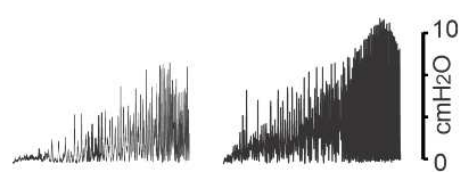

B. $24 \mathrm{~h}$ after SCI

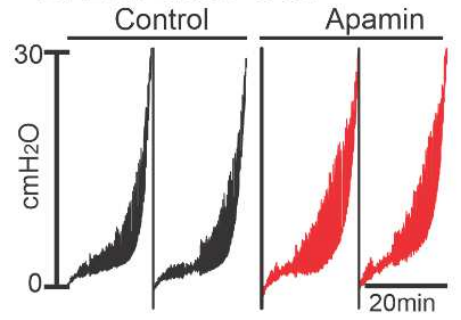

Ba. control

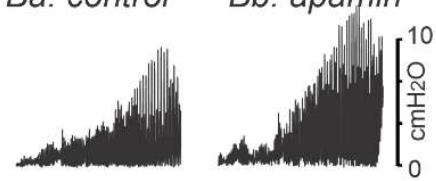

E. $14 d$ after SCI



Ea. control
Eb. apamin

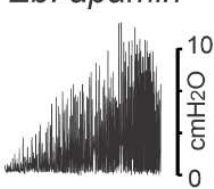

C. $72 \mathrm{~h}$ after $\mathrm{SCl}$

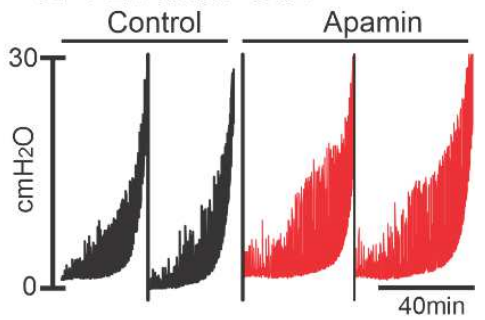

Ca. control

Cb. apamin



F. $30 d$ after SCl



Fa. control

Fb. apamin

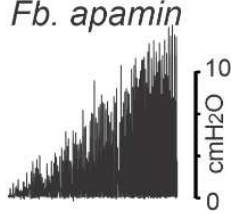

Figure 5: The effects of apamin on transient contractions (TCs) of sham, 1,3,7,14 and 30day after $\mathrm{SCl}$ using ex vivo preparation. A-F. Ex vivo pressure-response curve for control and apamin application. $\boldsymbol{A} \boldsymbol{a}, \boldsymbol{b}-\mathbf{F a}, \boldsymbol{b}$. Expanded time scales with adjustment of baseline under control (a) and apamin (b) from above panels. 
Table 1. Summarized data of frequency and amplitude before and after apamin.

\begin{tabular}{|l|r|r|r|r|}
\cline { 2 - 5 } \multicolumn{1}{c|}{} & \multicolumn{2}{c|}{$\begin{array}{c}\text { Peak Amplitude } \\
(\mathrm{cmH} 2 \mathrm{O})\end{array}$} & \multicolumn{2}{c|}{$\begin{array}{c}\text { Frequency } \\
\text { (events per min })\end{array}$} \\
\hline & \multicolumn{1}{c|}{ control } & \multicolumn{1}{c|}{ apamin } & \multicolumn{1}{c|}{ control } & apamin \\
\hline Sham $(\mathrm{n}=11)$ & $2.1 \pm 0.5$ & $6.9 \pm 1.2 \#$ & $22 \pm 9.1$ & $65 \pm 12.0 \#$ \\
\hline 1day $(\mathrm{n}=10)$ & $4.8 \pm 1.2^{*}$ & $7.2 \pm 1.5 \#$ & $52 \pm 9.7^{*}$ & $71 \pm 13.4$ \\
\hline 2day $(\mathrm{n}=12)$ & $5.1 \pm 0.6^{*}$ & $7.8 \pm 1.1 \#$ & $56 \pm 11.1^{*}$ & $69 \pm 11.7$ \\
\hline 3day $(\mathrm{n}=9)$ & $5.9 \pm 1.2^{*}$ & $7.2 \pm 1.4$ & $55 \pm 10.8^{*}$ & $64 \pm 9.2$ \\
\hline 14day $(\mathrm{n}=6)$ & $7.0 \pm 1.3^{*}$ & $8.3 \pm 2.3$ & $67 \pm 10.4^{*}$ & $69 \pm 11.6$ \\
\hline 30day $(\mathrm{n}=6)$ & $6.6 \pm 0.7^{*}$ & $6.9 \pm 0.5$ & $96 \pm 6.7^{*}$ & $98 \pm 4.1$ \\
\hline
\end{tabular}

${ }^{*} \mathrm{P}<0.05$ denotes comparison between sham and each period after $\mathrm{SCl}$. \# $\mathrm{P}<0.05$ denotes comparison of effects of apamin at each period.

Table 2. Summarized data of infusion volume and time to reach $30 \mathrm{cmH}_{2} 0$.

\begin{tabular}{|l|r|r|}
\cline { 2 - 3 } \multicolumn{1}{c|}{} & Infusion volume $(\mu \mathrm{l})$ & Infusion time $(\min )$ \\
\hline Sham $(\mathrm{n}=11)$ & $298 \pm 53$ & $11.9 \pm 2.0$ \\
\hline 1day $(\mathrm{n}=10)$ & $432 \pm 95^{*}$ & $24.3 \pm 4.1^{*}$ \\
\hline 2day $(\mathrm{n}=12)$ & $568 \pm 105^{*}$ & $23.5 \pm 4.7^{*}$ \\
\hline 3day $(\mathrm{n}=9)$ & $539 \pm 78^{*}$ & $24.1 \pm 3.9^{*}$ \\
\hline 14day $(\mathrm{n}=6)$ & $905 \pm 126^{*}$ & $36.2 \pm 5.0^{*}$ \\
\hline 30day $(\mathrm{n}=6)$ & $1108 \pm 67^{*}$ & $41.2 \pm 2.6^{*}$ \\
\hline
\end{tabular}

${ }^{*} \mathrm{P}<0.05$ denotes comparison between sham and each period after $\mathrm{SCl}$. 


\section{Figures}

A. Pdgfra

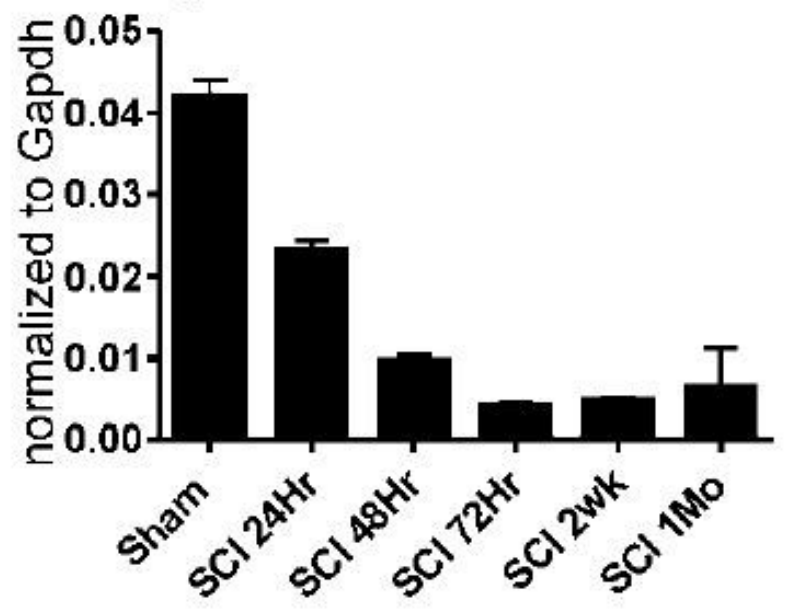

\section{C. sorted PDGFR $\alpha^{+}$cell}

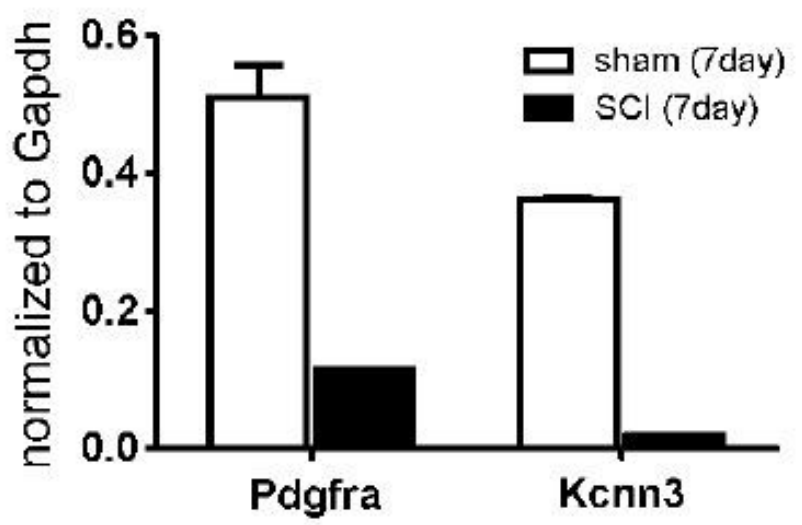

B. Kcnn3

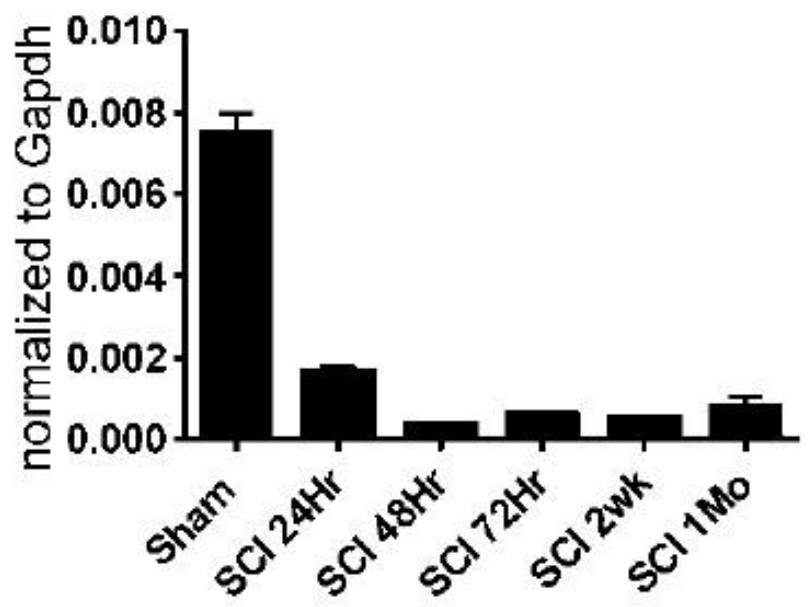

D. sorted SMC

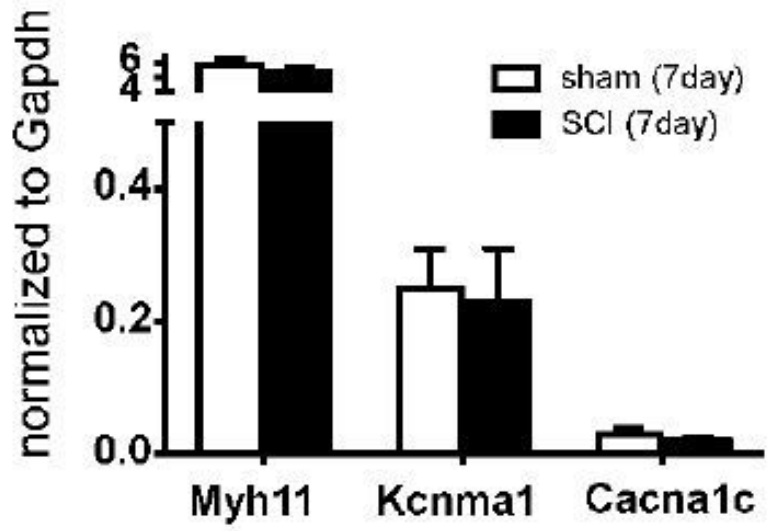

Figure 1

Quantitative analysis of transcripts in Sham and after SCl. A\&B. Pdgfra and Kcnn3 transcripts are decreased up to 1 month after $\mathrm{SCl}$ in detrusor muscles. C. Transcripts of Pdgfra and Kcnn3 from sorted PDGFRa+ cells in SCl (7day) decreased compared to sham (7day). D. Transcripts including Myh11, Kcnma1 and Cacna1C from sorted SMCs showed no significant change in $\mathrm{SCl}$ (7day). Error bars denote standard deviation from $n=4$. 


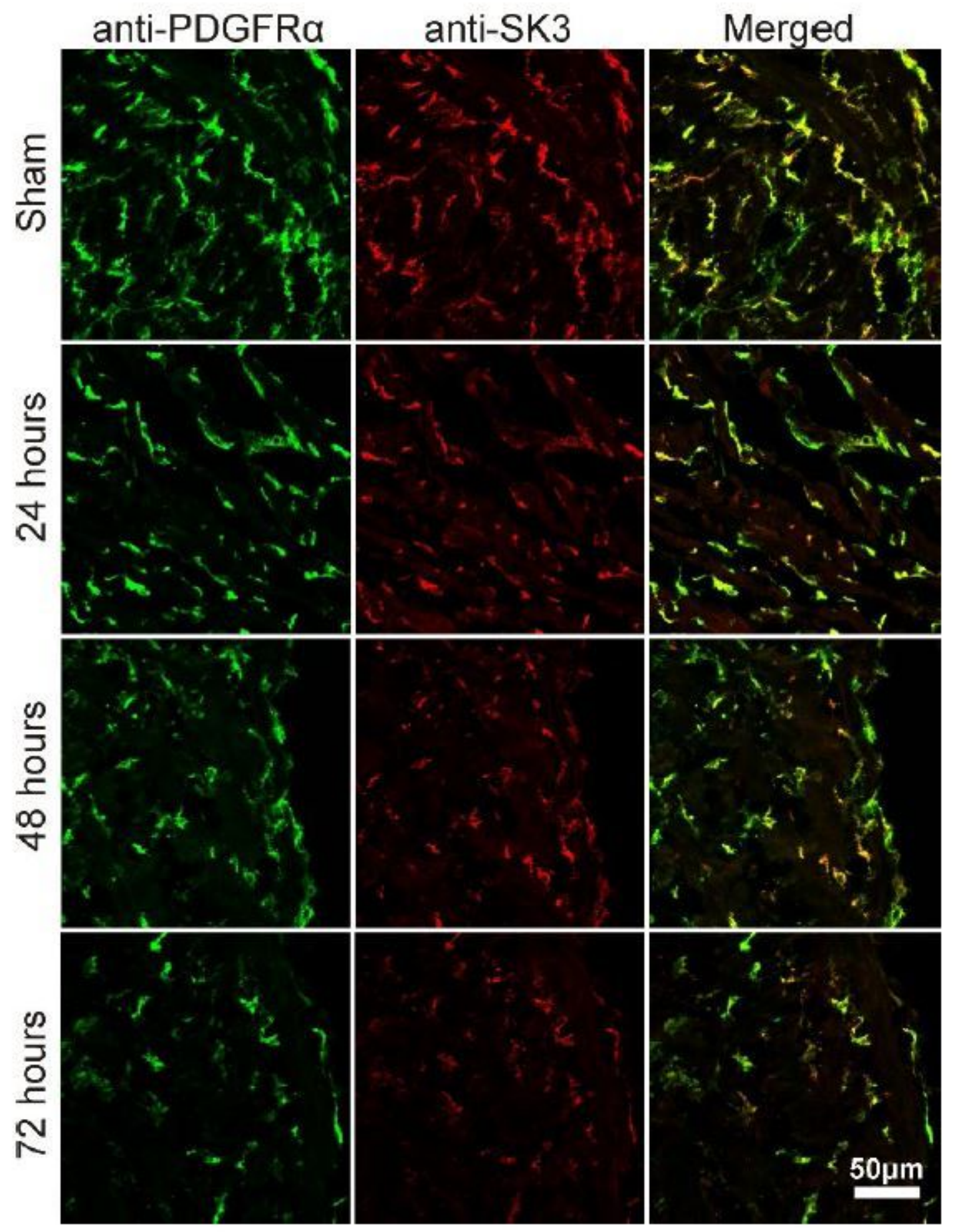

Figure 2

PDGFRa immunoreactivity of detrusor muscle layer in control and SCl. Immunoreactivity of PDGFRa (green) and SK3 (red) in control (sham). SCl (24hr, 48hr and $72 \mathrm{hr}$ ). 

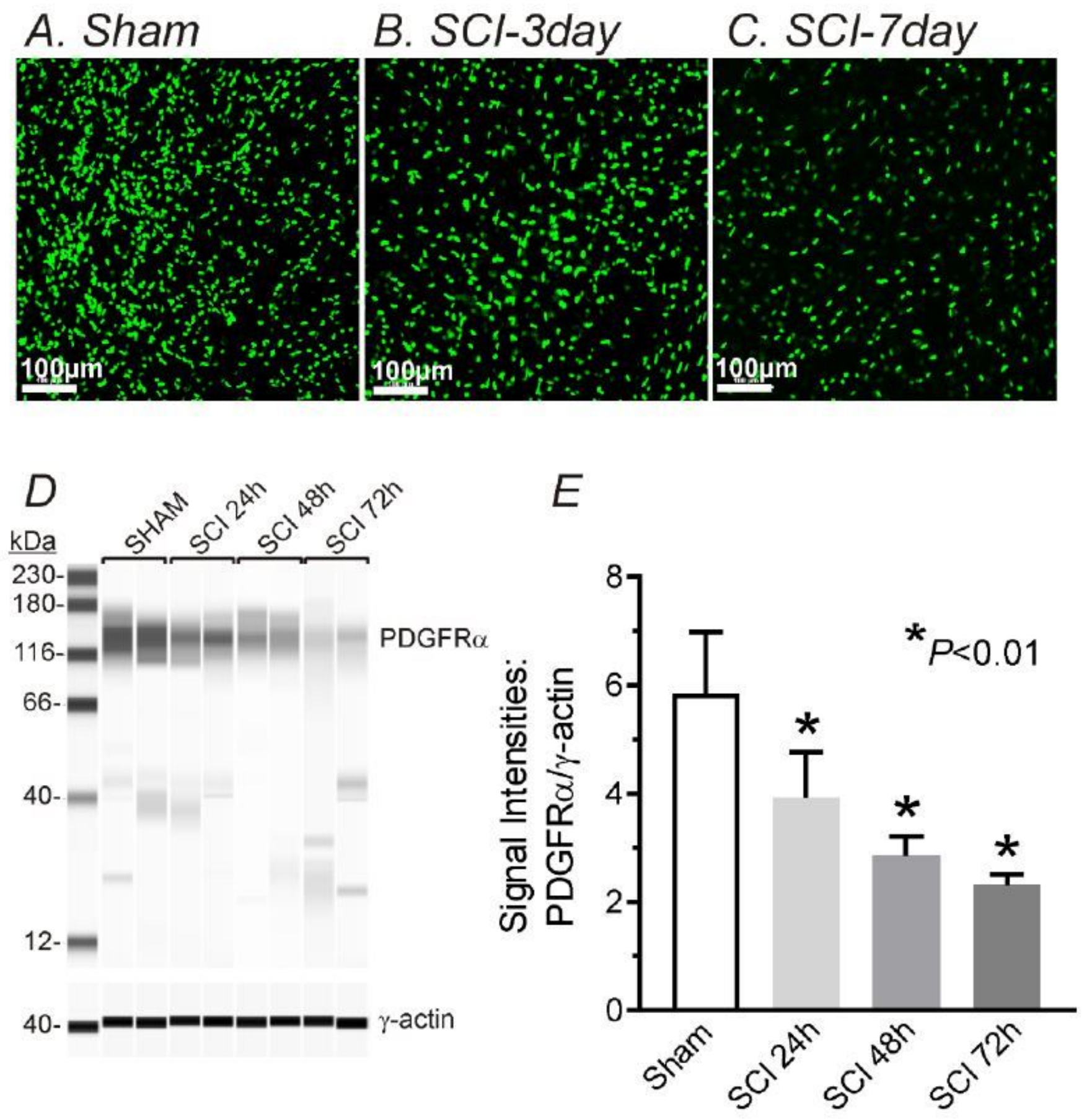

Figure 3

Density of PDFGRa/eGFP cells and Microcapillary electrophoresis and immunodetection of PDGFRa by WES in control and SCI detrusor muscles. A-C. Far fewer eGFP+ nuclei (reporter for PDGFRa+ cells) were found in detrusor muscles after SCl. D. Representative Wes full length gel image of PDGFRa expression in murine detrusor muscles following SCl. 100,000 x g pellet, $1 \mu \mathrm{g} /$ lane, $\gamma$-action was used for normalization. E. Normalized signal intensities of PDGFRa by g-actin following SCl periods. 

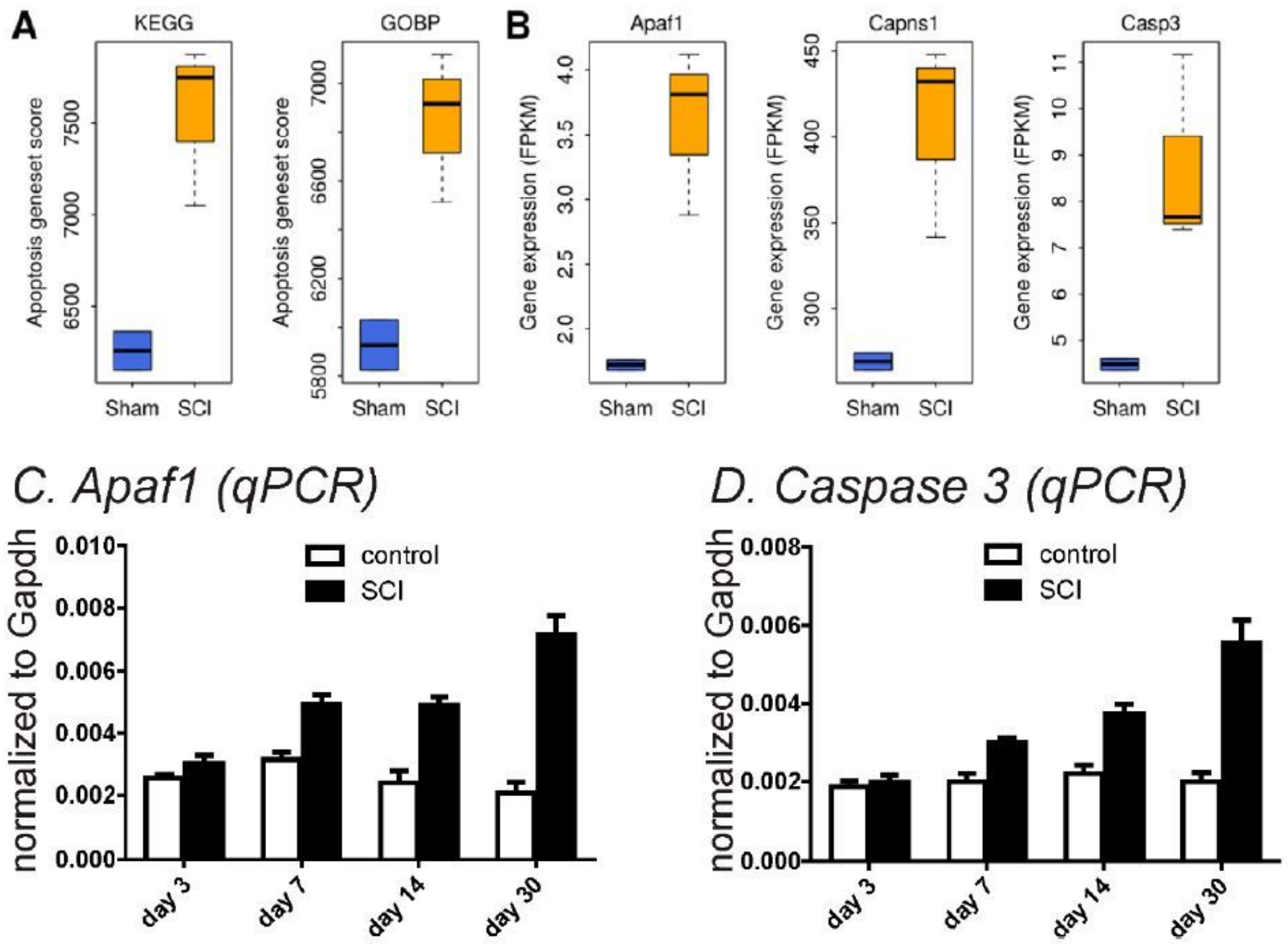

Figure 4

SCl -induced alteration in apoptosis-related genes by RNA-seq (A \&B) and GPCR (C \& D). A. Apoptosis geneset scores upregulated in SCI for both the KEGG and GOBP definitions. B. Expression of three apoptosis-related genes were upregulated in SCl. C \& D. qPCR from sorted PDGFRa+ cells in SCl up to 30days showed an increase in apoptosis-related transcripts (Apaf1 in C and Caspase3 in D). 
A. Sham

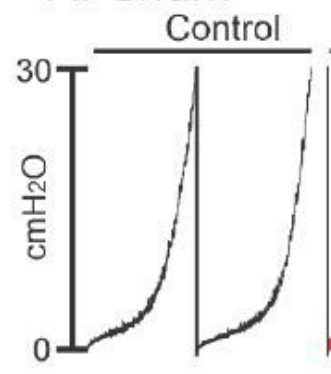

Aa. control

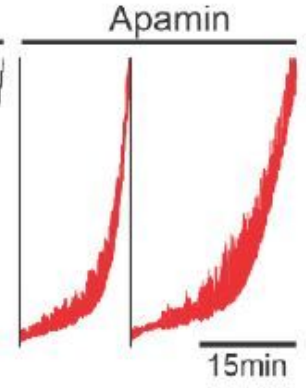

Ab. apamin

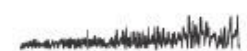

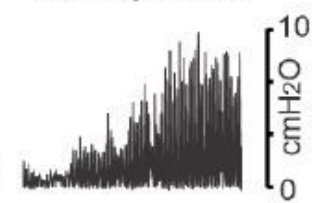

D. $7 d$ after $\mathrm{SCl}$

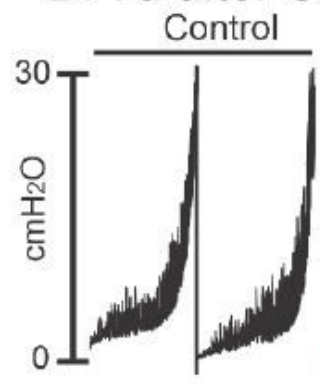

Da. control

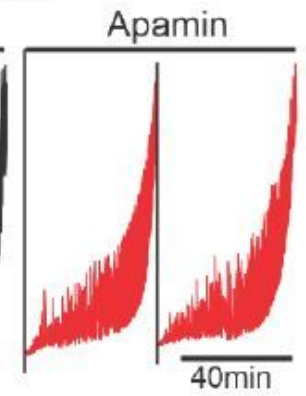

Db. apamin

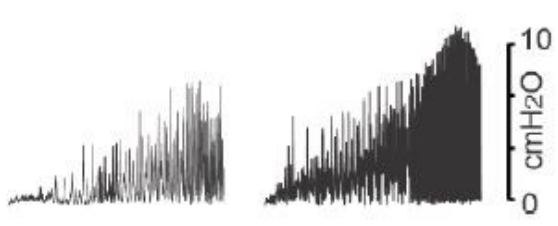

B. $24 \mathrm{~h}$ after $\mathrm{SCl}$

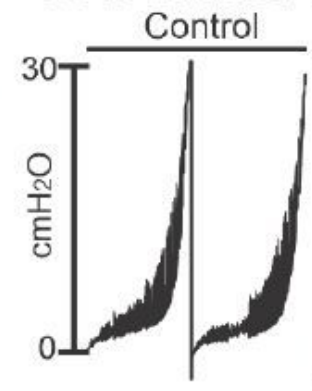

Ba. control

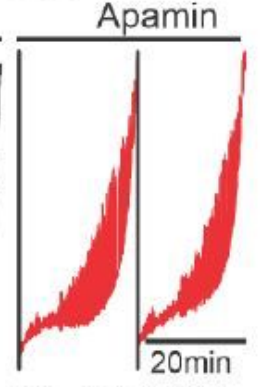

Bb. apamin

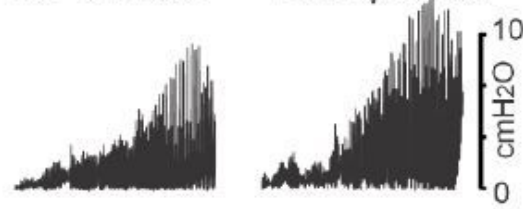

E. $14 d$ after SCI

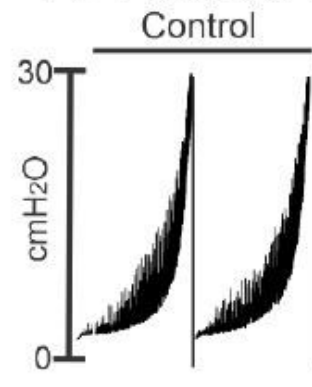

Ea. control

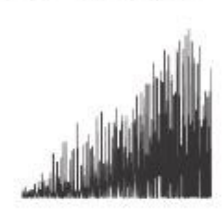

C. $72 h$ after $\mathrm{SCl}$

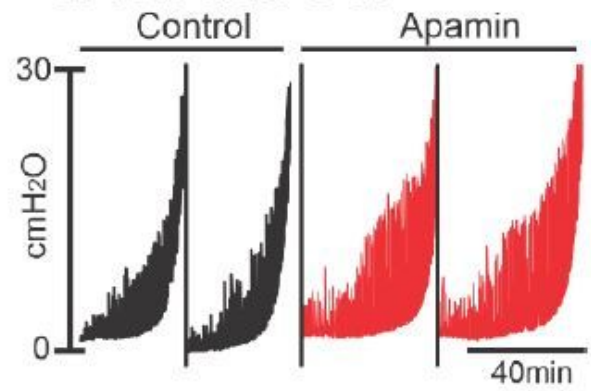

Ca. control

Cb. apamin
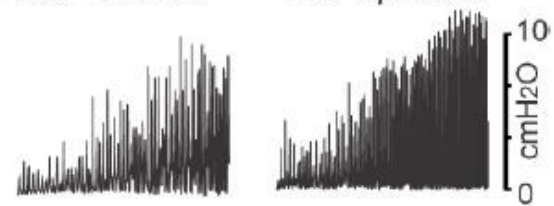

F. $30 d$ after SCl

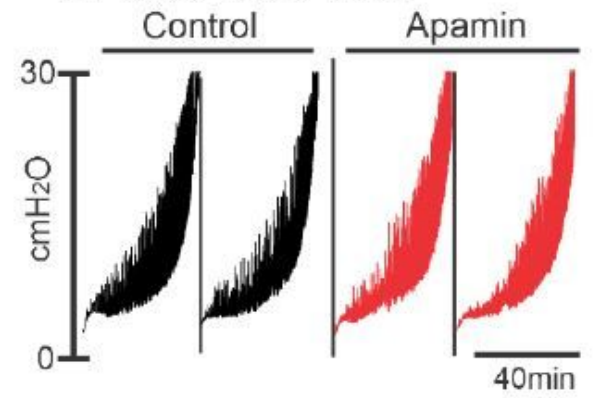

Fa. control

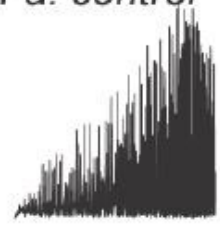

Fb. apamin

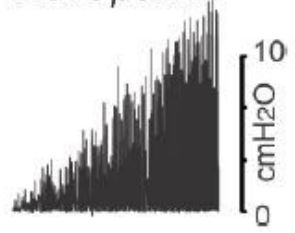

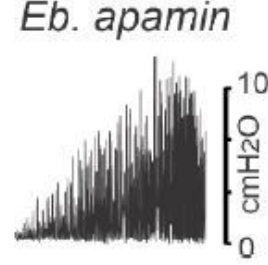

\section{Figure 5}

The effects of apamin on transient contractions (TCs) of sham, 1,3,7,14 and 30day after SCl using ex vivo preparation. A-F. Ex vivo pressure-response curve for control and apamin application. Aa,b-Fa,b. Expanded time scales with adjustment of baseline under control (a) and apamin (b) from above panels. 